\title{
Assessment of the Performance Potential of Advanced Subsonic Transport Concepts for NASA's Environmentally Responsible Aviation Project
}

\author{
Craig L. Nickol ${ }^{1}$ \\ NASA Langley Research Center, Hampton, VA \\ William J. Haller ${ }^{2}$ \\ NASA Glenn Research Center, Cleveland, $\mathrm{OH}$
}

\begin{abstract}
NASA's Environmentally Responsible Aviation (ERA) project has matured technologies to enable simultaneous reductions in fuel burn, noise, and nitrogen oxide (NOx) emissions for future subsonic commercial transport aircraft. The fuel burn reduction target was a $\mathbf{5 0 \%}$ reduction in block fuel burn (relative to a 2005 best-in-class baseline aircraft), utilizing technologies with an estimated Technology Readiness Level (TRL) of 4-6 by 2020. Progress towards this fuel burn reduction target was measured through the conceptual design and analysis of advanced subsonic commercial transport concepts spanning vehicle size classes from regional jet (98 passengers) to very large twin aisle size (400 passengers). Both conventional tube-and-wing $(\mathrm{T}+\mathrm{W})$ concepts and unconventional (over-wing-nacelle $(\mathrm{OWN})$, hybrid wing body (HWB), mid-fuselage nacelle (MFN)) concepts were developed. A set of propulsion and airframe technologies were defined and integrated onto these advanced concepts which were then sized to meet the baseline mission requirements. Block fuel burn performance was then estimated, resulting in reductions relative to the 2005 best-in-class baseline performance ranging from $39 \%$ to $49 \%$. The advanced single-aisle and large twin aisle $T+W$ concepts had reductions of $43 \%$ and $41 \%$, respectively, relative to the $737-800$ and 777-200LR aircraft. The single-aisle OWN concept and the large twin aisle class HWB concept had reductions of $45 \%$ and $47 \%$, respectively. In addition to their estimated fuel burn reduction performance, these unconventional concepts have the potential to provide significant noise reductions due, in part, to engine shielding provided by the airframe. Finally, all of the advanced concepts also have the potential for significant NOx emissions reductions due to the use of advanced combustor technology. Noise and NOx emissions reduction estimates were also generated for these concepts as part of the ERA project.
\end{abstract}

\section{Introduction}

$\mathrm{N}$ ASA created the Environmentally Responsible Aviation (ERA) project in 2009. At the time of formulation, stable funding and consistent fundamental research direction were producing promising concepts and technologies that had the potential for further maturation at the system level in a relevant environment. The NASA Advisory Council called for NASA's Aeronautics Research Mission Directorate to plan and develop candidate systems-level research projects, consistent with the National Aeronautics Policy and Plan and leveraging NASA's unique expertise and competencies, to advance the state-of-the-art capabilities in key disciplines and facilitate transition of results to the aerospace community. In addition, there was strong support from industry for new system research plans. Finally, Congress supported this direction through FY10 appropriations funding the beginning of ERA. The ERA portfolio was focused on conducting research at an integrated system level on promising concepts and technologies and exploring, assessing, or demonstrating the benefits in a relevant environment (up to TRL=6). The criteria utilized for selection of projects were:

\footnotetext{
${ }^{1}$ Senior Aerospace Engineer, Aeronautics Systems Analysis Branch, MS 442, AIAA Senior Member

${ }^{2}$ Senior Aerospace Engineer, Propulsion Systems Analysis Branch, MS 5-11
}

1

American Institute of Aeronautics and Astronautics 
- Technologies have attained enough maturity in the foundational research program that they merit more in-depth evaluation at an integrated system level in a relevant environment

- Technologies which systems analysis indicates have the most potential for contributing to the simultaneous attainment of technical goals

- Research not being done by other government agencies and appropriate for NASA to conduct

The ERA project focused on exploring new vehicle concepts and enabling technologies through system level experimentation to simultaneously reduce fuel burn, noise, and Landing Takeoff (LTO) NOx emissions. Figure 1 is NASA's subsonic transport system level metrics chart. The focus of ERA was on the "N+2" technology generation, defined as containing technologies that have the potential to mature to a TRL level of 4-6 by 2020 .

\begin{tabular}{|c|c|c|c|}
\hline \multirow{2}{*}{$\begin{array}{l}\text { TECHNOLOGY } \\
\text { BENEFITS* }\end{array}$} & \multicolumn{3}{|c|}{$\begin{array}{c}\text { TECHNOLOGY GENERATIONS } \\
\text { (Technology Readiness Level }=4-6 \text { ) }\end{array}$} \\
\hline & $\mathrm{N}+1$ (2015) & $N+2\left(2020^{\star \star}\right)$ & $\mathrm{N}+3(2025)$ \\
\hline $\begin{array}{c}\text { Noise } \\
\text { (cum margin rel. to Stage 4) }\end{array}$ & $-32 d B$ & $-42 d B$ & $-52 \mathrm{~dB}$ \\
\hline $\begin{array}{l}\text { LTO NOx Emissions } \\
\text { (rel. to CAEP 6) }\end{array}$ & $-60 \%$ & $-75 \%$ & $-80 \%$ \\
\hline $\begin{array}{l}\text { Cruise NOx Emissions } \\
\text { (rel. to } 2005 \text { best in class) }\end{array}$ & $-55 \%$ & $-70 \%$ & $-80 \%$ \\
\hline $\begin{array}{l}\text { Aircraft Fuel/Energy Consumption }{ }^{\ddagger} \\
\text { (rel. to } 2005 \text { best in class) }\end{array}$ & $-33 \%$ & $-50 \%$ & $-60 \%$ \\
\hline
\end{tabular}

\footnotetext{
* Projected benefits once technologies are matured and implemented by industry. Benefits vary by vehicle size and mission. $\mathrm{N}+1$ and $\mathrm{N}+3$ values are referenced to a 737-800 with CFM56-7B engines, $\mathrm{N}+2$ values are referenced to a 777-200 with GE90 engines

** ERA's time-phased approach includes advancing "long-pole" technologies to TRL 6 by 2015

$\ddagger \mathrm{CO} 2$ emission benefits dependent on life-cycle CO2e per MJ for fuel and/or energy source used
}

Figure 1. NASA subsonic transport system level metrics chart.

The N+2 targets for noise, LTO NOx emissions, and fuel burn are enclosed within a green box to indicate that the ERA goal is to meet these targets simultaneously by focusing on advanced concepts and technologies and highly integrated engine/airframe configurations. Since the only current certification standard for NOx is LTO NOx, the cruise NOx emissions target was considered a secondary priority and is not addressed in this study. Although not considered in this study, a cruise NOx standard is quite likely at some future date and will require advanced combustors to maintain high efficiency at operating conditions throughout the flight envelope. The fuel burn target is a $50 \%$ block fuel burn reduction relative to a 2005 best-in-class baseline. As stated in the notes in Figure 1, the $\mathrm{N}+2$ values are referenced to a 777-200 with GE90 engines. Therefore, the Large Twin Aisle (LTA) class aircraft represented by the 777 was the primary focus of the ERA systems analysis; however, smaller and larger vehicles were also analyzed to capture technology scaling effects.

This study focused on the potential for $\mathrm{N}+2$ technology generation concepts to meet the fuel burn reduction target shown in Figure 1. To accomplish this, a family of $\mathrm{N}+2$ concepts was developed at the conceptual level, and their fuel burn performance was compared to 2005 best-in-class baseline aircraft. These $\mathrm{N}+2$ concepts spanned the vehicle class range from regional jets to very large twin aisle designs, including both tube-and-wing $(\mathrm{T}+\mathrm{W})$ and unconventional concepts. Table 1 lists the full set of $\mathrm{N}+2$ concepts developed for this study. Two versions of the T+W301 and hybrid-wing-body-301 (HWB301) concepts were developed, one utilizing direct drive (DD) engines, the other utilizing geared turbofan engines (GTF). These will be referred to as T+W301-DD, T+W301-GTF, HWB301-DD, and HWB301-GTF. 
Table 1. Study Concept Nomenclature

\begin{tabular}{|r|c|c|c|c|c|}
\hline \multicolumn{1}{|c|}{ Vehicle Class } & Abbreviation & $\begin{array}{c}\text { Number of } \\
\text { Passengers }\end{array}$ & $\begin{array}{c}\mathrm{N}+2 \mathrm{~T}+\mathrm{W} \\
\text { Nomenclature }\end{array}$ & Unconventional & Abbreviation \\
\hline Regional Jet & RJ & 98 & T+W98 & Over-Wing-Nacelle & OWN98 \\
\hline Single Aisle & SA & 160 & T+W160 & Over-Wing-Nacelle & OWN160 \\
\hline Large Twin Aisle & LTA & 301 & T+W301 & $\begin{array}{c}\text { Hybrid-Wing-Body } \\
\text { Mid-Fuselage Nacelle }\end{array}$ & $\begin{array}{c}\text { HWB301 } \\
\text { MFN301 }\end{array}$ \\
\hline Very Large Twin Aisle & VLTA & 400 & T+W400 & Hybrid-Wing-Body & HWB400 \\
\hline
\end{tabular}

The $\mathrm{N}+2$ concepts were utilized to integrate the set of technologies that have been matured by the ERA project, along with additional technologies expected to mature by the $\mathrm{N}+2$ timeframe. The next section describes technologies matured as part of the ERA project.

\section{ERA Technology Maturation}

The ERA project culminated in the completion of a large number of sub-system tests that were intended to mature the selected technologies. Eight Integrated Technology Demonstrations (ITDs) were created and results from the ITD testing were utilized to form the input assumptions for the system level modeling. The following section provides a brief overview of each ITD. Section III, Vehicle Modeling, will present the data and assumptions derived from these ITDs that were utilized for the system level modeling.

\section{A. ITD 12A+ Active Flow Control (AFC) Enhanced Vertical Tail plus Advanced Wing Flight Experiment}

The AFC Enhanced Vertical Tail and Advanced Wing Flight Experiment ITD investigated two promising technologies. The first technology was demonstrated by testing the effectiveness of blowing a row of small unsteady jets across a rudder's leading edge, enhancing the rudder performance and allowing for vertical tail size reductions on future transport aircraft. This is particularly attractive when considering an aircraft family concept. To reduce costs, identical vertical tail assemblies are utilized across the family, resulting in over-sized tails for the stretch models (the vertical tail area is set by the shorter fuselage/moment arm, and as the fuselage length/tail moment arm is increased, less tail area is needed). By utilizing AFC technology on the shorter fuselage version, the tail sizes can be kept smaller on the stretch versions. This AFC technology will result in a size and weight reduction of the vertical tail and rudder that translates to a reduction in fuel burn and greenhouse gas emissions. See Lin, et al. ${ }^{1}$ for more detail. The second technology maturation task was Insect Accretion Mitigation (IAM), which mitigates the aerodynamic effects of insect accretions on wings. One of the challenges for implementing laminar flow on wings is premature loss of laminar flow from roughness induced by insect contamination. The IAM research involved the investigation of insect protection coating technologies used to mitigate wing and leading edge insect residue adhesion in order to enhance and maintain laminar flow on the wing. See Lin, et al. ${ }^{2}$ for more detail. Both technologies were flight tested at full scale on the Boeing ecoDemonstrator 757 aircraft in 2015.

\section{B. ITD 21A Damage Arresting Composites Demonstration}

Boeing and NASA have developed the Pultruded Rod Stitched Efficient Unitized Structure (PRSEUS) concept which provides stiffness in both in-plane directions to support flight loads and internal pressure loads. This advanced structural technology is a key enabler for the centerbody section of the HWB concept. In addition, the use of stitched resin infused (S/RI) composites, of which PRSEUS is a specific instantiation, has the potential to reduce structural weight for any concept. ERA partnered with Boeing in the fabrication and testing of the Multi-Bay Box (MBB) test article that is representative of a HWB centerbody cross-section between the wings at $80 \%$ scale. The approach for the experiment was to position the MBB in the Combined Loads Test System (COLTS) at the NASA Langley Research Center (LaRC) and subject it to a series of loadings to prove that it can withstand the design ultimate loads (DUL) and that the measured behavior agrees with analytical predictions. In 2015, the MBB was successfully tested to pressure loading up to the FAA-required pressure load of $2 \mathrm{P}(18.4 \mathrm{psi})$, bending loads corresponding to $+2.5 \mathrm{G}$ (up-bending), -1G (down-bending), and the combination of pressure up-bending and down-bending load conditions. See Jegley, et al. ${ }^{3}$ or Li and Linton ${ }^{4}$ for details. 


\section{ITD 21C Adaptive Compliant Trailing Edge (ACTE) Flight Experiment}

The ACTE ITD was focused on weight and drag reduction through the use of adaptive compliant structures. ERA partnered with the Air Force Research Laboratory (AFRL) who is sponsoring the development of adaptive compliant wing technology through the Small Business Innovation Research (SBIR) program with FlexSys, Inc. The ACTE technology will result in size and weight reductions for aircraft wings that translate to reductions in fuel burn and greenhouse gas emissions. The ACTE technology was matured in this ITD with a compliant flap designed for integration and flight testing on the NASA Armstrong Gulfstream III aircraft. Successful flight tests in 2015 increased the ACTE technology TRL to 6. See Miller, et al. ${ }^{5}$, and Herrera, et al. ${ }^{6}$ for details presented at the 2015 Society of Flight Test Engineers Symposium. Also, see Miller, et al. ${ }^{7}$, Herrera, et al. ${ }^{8}$, and Cruz, et al. ${ }^{9}$, for additional information on the ACTE technology and flight testing.

\section{ITD 30A Highly Loaded Front Block Compressor}

In order to make improvements in aircraft engine overall efficiency, and thus reductions in thrust specific fuel consumption (TSFC) and fuel burn, increases in both propulsive efficiency and engine core thermal efficiency are sought. This ITD targeted increased core thermal efficiency, specifically through a significant boost in an engine's overall pressure ratio via a pressure ratio increase in the high pressure compressor (HPC). To achieve this objective without having to add multiple stages, which increases weight/complexity, the capability of the HPC's "front block" (first 3 stages) must be enhanced through increased stage loading while simultaneously maintaining compressor efficiency comparable to state-of-the-art HPCs. Technology development and maturation activities focused on improving the pressure rise across the first three stages of a 30:1 class HPC. Test activities included base-lining HPC front block efficiency and operability and demonstrating improved front block pressure gains while maintaining adequate efficiency and stall margin. Ground tests conducted at Glenn Research Center were successfully concluded in 2015 .

\section{E. ITD 35A 2nd Generation Geared Turbofan Propulsor}

The direction of turbofan technology has been moving toward higher engine bypass ratios (BPR) and lower fan pressure ratios (FPR). As the BPR increases and the corresponding FPR decreases, the amount of fuel burned decreases. However, the fan diameter must increase to produce the same amount of thrust resulting in a larger engine nacelle diameter. This creates additional drag at higher flight speeds, meaning more thrust is needed to overcome the higher drag. Since noise is also a critical consideration in engine design, fan speed should be kept as low as possible to minimize the noise signature. However, lower fan speeds mean lower compressor and turbine component speeds in the engine core as well, since a common drive shaft connects the core components and the fan. A specific amount of power is needed to drive the fan for a given thrust; as the fan design speed drops, the turbine must get larger in size, both in number of stages and overall diameter, to produce the needed power. Larger components mean more weight, and more fuel burn to carry that weight around. To mitigate these problems, a gearbox has been utilized. Decoupling the fan from the other components on the shaft enables each machine to operate closer to its optimal speed. Pratt \& Whitney's PW1000G is prepared to become the first geared turbofan (GTF) engine to enter service on a commercial aircraft ${ }^{10}$. The goal of this ITD is to help extend the fuel burn advantage trend line with increasing BPR in spite of the challenging trade-offs discussed above. To that end, the aerodynamic performance, operability, and noise characteristics of a 2nd Generation GTF technology for both conventional and advanced nacelles with lower weight and drag were tested.

\section{F. ITD 40 Low NOx Fuel Flexible Combustor}

A series of increasingly stringent LTO NOx emission standards by the International Civil Aviation Organization's (ICAO) Committee on Aviation Environmental Protection (CAEP) over the years has limited aviation emissions below 3,000-foot altitudes. These standards cover the landing, takeoff, descent, and taxiing phases of engine operation in a prorated fashion. ERA's target was to develop and demonstrate a low NOx, fuel flexible combustor that provides a 75\% reduction in NOx below the CAEP/6 standard with no increase in particulate matter, and minimal impact on the fuel burn and noise targets. To meet the fuel burn reduction targets, advanced engines will be operating at higher pressures and temperatures that encourage NOx production. Improving specific fuel consumption while simultaneously reducing NOx requires advanced combustor technology. New injector 
designs and air/fuel mixing concepts, such as lean direct injection, will be required to meet the emissions targets and provide fuel flexibility; however, leaner-burn concepts tend to have less stability margin and require fuel staging and combustion control. This ITD reduced the risk of meeting the emission targets through sector rig and full annular testing of advanced combustors. See Van Zante ${ }^{11}$ for more details on ITDs 30A, 35A, and 40.

\section{G. ITD 50A Flap Edge and Landing Gear Noise Reduction}

The full evaluation of noise reduction at the aircraft system level must consider both engine noise and airframe noise contributions. Considerable research in quiet engine technologies has resulted in significant reductions in engine noise during takeoff and landing operations. For current state-of-the-art aircraft, it is generally accepted that, on the landing approach, engine and airframe noise are comparable. Therefore, further reductions in community exposure to aircraft noise must also include airframe noise abatement. The main sources of airframe noise are the wing high-lift system (slats and flaps) and the undercarriage (nose and main landing gear). The Flap Edge and Landing Gear Noise Reduction (FE\&LG NR) ITD developed 1) advanced tools and capabilities that enabled concurrent aerodynamic and acoustic design considerations to be integrated into airframe design cycles, and 2) effective noise reduction concepts that will contribute to meeting ERA's noise reduction goal. For flaps, these concepts directly affect the noise source regions at the side edges (tips) by altering the local steady and fluctuating fields. The noise reduction concepts for the main landing gear involve fairings that alter the local flow field impinging on various gear components in a way that minimizes the pressure fluctuations (noise sources) on the gear surfaces. A number of flap edge and main landing gear noise reduction concepts were investigated during wind tunnel tests of an $18 \%$ scale, semi-span aircraft model. See Khorrami, et al. ${ }^{12}$ and Khorrami, Humphreys and Lockard $^{13}$ for more detail.

\section{H. ITD 51A Ultra-High-Bypass (UHB) Ratio Engine Integration for Hybrid-Wing-Body Concepts}

Aircraft engines are a significant contributor to aircraft community noise. Virtually all of the large-scale engineairframe performance information comes from conventional $\mathrm{T}+\mathrm{W}$ configurations with engine pods hanging below the wings. Alternate configurations, such as hybrid wings with top-mounted engines and low-wing $\mathrm{T}+\mathrm{W}$ concepts having over-the-wing mounted nacelles, may provide shielding benefits to reduce community noise. In the HWB configuration, the efficient integration of twin UHB turbofan engines will be critical to success from a performance (drag and stability and control), engine operability, and noise shielding perspective. Through extensive CFD analyses and wind tunnel testing, this ITD addressed two major areas of interest in the development of this technology:

- Aerodynamic Efficiency: Details of actual engine integration such as nacelle size and location relative to oncoming flows, vertical tails, and the aft deck are extremely important to interference drag effects as well as stability and control of a HWB configuration.

- Engine Operability: The operability of the inlets, fans, and nozzles resulting from the flow angularity driven by dominate flow-field features of an HWB configuration at low speeds, high angle-of-attack and crosswind operation must be examined before the HWB concept is considered a viable technology option for commercial transport vehicles.

See Flamm, et al. ${ }^{14}$, for additional details.

\section{Vehicle Modeling}

The following section describes the development of the $\mathrm{N}+2$ concept vehicle models, including propulsion and airframe modeling for both conventional and unconventional concepts.

\section{A. Baseline Models}

Table 2 shows the five baseline aircraft utilized to calculate the fuel burn metric. 
Table 2. Baseline Aircraft

\begin{tabular}{|c|c|c|c|c|c|}
\hline & Class & $\begin{array}{c}2005 \text { Best-in-class } \\
\text { Baseline }\end{array}$ & \# Pax & $\begin{array}{c}\text { Design } \\
\text { Range }(\mathrm{nm})\end{array}$ & $\begin{array}{c}\text { Baseline Engine } \\
\text { Model }\end{array}$ \\
\hline RJ & Regional Jet & ERJ-190 & 98 & 2400 & CF34-10E \\
\hline SA & Single Aisle & $737-800$ & 160 & 2875 & CFM56-7B \\
\hline STA & Small Twin Aisle & $767-200 E R$ & 216 & 6600 & PW4056 \\
\hline LTA & Large Twin Aisle & $777-200$ LR & 301 & 7500 & GE90-110 \\
\hline VLTA & Very Large Twin Aisle & $747-400$ & 400 & 5800 & PW4056 \\
\hline
\end{tabular}

Payload/range, weights, and geometry data from public sources were utilized to develop the models. For example, in the case of the LTA baseline, data from Boeing contained in their airplane characteristics for airport planning documentation was utilized ${ }^{15}$. In all cases, a design mission was selected and the zero fuel weight, operating empty weight, payload weight, range, and total fuel weight associated with the design mission were obtained. Geometric inputs were taken from scaled 3-view drawings provided in the documentation. The engine models were obtained from the Propulsion Systems Analysis Branch at NASA's Glenn Research Center (GRC). Engines were modeled using GRC's standard tools and process including NPSS ${ }^{16}$ and WATE $+{ }^{17}$. NPSS is an engine cycle analysis tool developed jointly by NASA and U.S. industry. It is currently the accepted, state-of-the-art software for air breathing engine cycle performance analysis for the U.S. aerospace industry, academia and NASA. NPSS estimates engine performance (thrust, ram drag, fuel flow, etc.) for any desired flight condition. The NASA software tool WATE++ (Weight Analysis of Gas Turbine Engines) is used to create an engine component architecture that matches the engine thermodynamic cycle produced by NPSS. The cycle data required for WATE execution, such as airflow, temperatures, pressures, pressure ratios, etc., were derived from the NPSS cycle model output. The final required input to model the baseline vehicles was low speed aerodynamic data. The MVL-15 ${ }^{18}$ code was utilized to estimate takeoff and landing drag polars for the $\mathrm{T}+\mathrm{W}$ concepts.

The Flight Optimization System ${ }^{19}$ (FLOPS) code, a NASA aircraft sizing and synthesis design tool, was utilized to create full vehicle models. The design mission data, low speed aerodynamics, geometry and engine decks were loaded as inputs, and the weights were then calibrated to be consistent with the published data. The calibration process was completed using the analysis mode in FLOPS. The analysis mode is a single pass analysis of a given set of inputs with no optimization. Once the model is reasonably calibrated (all values within $+/-1 \%$ ), the FLOPS optimization capability was then utilized as the final step. This is an important step to avoid overly optimistic advanced vehicle estimates since the $\mathrm{N}+2$ vehicle designs will be created using the optimization capability. By optimizing the baseline and then using the same objective function, design variables, and constraints for the $\mathrm{N}+2$ vehicles, a consistent comparison can be made. Table 3 summarizes the optimization problem formulation.

Table 3. Optimization Problem Formulation

\begin{tabular}{|r|l|}
\hline Objective Function & Minimize Takeoff Gross Weight \\
\hline Design Variables & Thrust, Wing Area \\
\hline Constraints & Range \\
& Approach Speed \\
& Takeoff Field Length \\
& Landing Field Length \\
& $\begin{array}{l}\text { Missed Approach Net Thrust } \\
2^{\text {nd }} \text { Segment Climb Net Thrust } \\
\text { Excess Fuel Capacity } \\
\text { Rate of Climb at Top of Climb }\end{array}$ \\
\hline
\end{tabular}

The fuel burn results from the optimization process are shown in Table 4. Total fuel values for the selected design missions are shown, and the FLOPS optimization results are compared to the published data. The associated block fuel values are used for the fuel burn metric calculations. As stated above, the target is to reduce the block fuel burn by $50 \%$, shown by the block fuel burn targets in Table 4 . It is important to note that the optimized baseline vehicles are no longer calibrated to the actual aircraft values since FLOPS will adjust wing area and thrust to meet the given 
constraints resulting in baselines that are like the actual aircraft but not identical. This is required since the $\mathrm{N}+2$ models will be optimized using the same formulation enabling a direct and consistent comparison between the baseline and $\mathrm{N}+2$ concepts.

Table 4. Baseline Fuel Burn Modeling Results

\begin{tabular}{|l|c|c|c|c|c|c|}
\hline & & $\begin{array}{c}\text { ERJ190 } \\
\text { CF34-10E }\end{array}$ & $\begin{array}{c}\text { 737-800 } \\
\text { CFM56-7B }\end{array}$ & $\begin{array}{c}\text { 767-200ER } \\
\text { PW4056 }\end{array}$ & $\begin{array}{c}\mathbf{7 7 7 - 2 0 0 L R} \\
\text { GE90-110 }\end{array}$ & $\begin{array}{c}\mathbf{7 4 7 - 4 0 0} \\
\text { PW4056 }\end{array}$ \\
\hline Published Total Fuel & Ib & 28,660 & 45,637 & 160,600 & 307,000 & 334,500 \\
\hline FLOPS Total Fuel & Ib & 28,714 & 46,821 & 161,227 & 306,875 & 334,242 \\
\hline Total Fuel \% Delta & & 0.19 & 2.59 & 0.39 & -0.04 & -0.08 \\
\hline FLOPS Block Fuel & Ib & 24,252 & 39,107 & 144,553 & 277,133 & 297,616 \\
\hline 50\% Target Block Fuel & Ib & 12,126 & 19,554 & 72,277 & 138,567 & 148,808 \\
\hline
\end{tabular}

\section{B. Advanced (N+2) Propulsion Modeling}

The technology assumptions utilized to develop the engine models were consistent with the N+2 timeframe. Where applicable, data from in-house/contractor tests or high-fidelity computational predictions were leveraged from the propulsion related ITDs and captured in the NPSS/WATE++ models.

NPSS and WATE were both modified to capture the impact of ITD 30A. This technology is specifically envisioned for an HPC typically found in a DD engine. Therefore, NPSS was used to develop an N+2 DD engine for the LTA vehicles. The HPC pressure ratio was increased to 27 (from a current technology value of 20 for this engine class) to represent an advanced HPC target. WATE++ was configured (via loading input) to match the front block compressor (3 stages) pressure ratio that was tested in NASA GRC's compressor facility.

For ITD 35A, NPSS fan maps based on computational predictions for an $\mathrm{N}+2$ engine cycle were utilized. The maps analytically represent fan rotor performance as a combination of pressure ratio, airflow and efficiency across an array of operating speeds. To account for the effects of the static structure that comprise the remainder of the propulsor, a "loss model" methodology was used. This enables the engine model to calculate losses in the bypass stream due to the fan exit guide vanes and accounts for the effects of fan rotor exit swirl.

In addition to the ITDs described above, a number of other technologies were assumed as viable for inclusion given the N+2 timeframe. Specifically, ceramic-matrix composites were employed in the high-pressure turbine stators. These composites are able to withstand higher temperatures than a typical metal blade and allow for a reduction in turbine cooling flow levels. Also, the composite stators are lighter than the metal versions, so a slight weight benefit was captured as well. As engine diameters increase due to lower fan pressure ratio and lower specific thrust, the inlet $\mathrm{L} / \mathrm{D}$ has been reduced to minimize scrubbing drag. The current vision is these inlets will maintain the inlet recovery levels of current inlets (so no performance impact), but the smaller L/D enabled an inlet weight savings for the $\mathrm{N}+2$ engines.

Table 5 shows the results of the $\mathrm{N}+2$ engine modeling for all of the concepts except the large HWBs. Data is given at two conditions, TOC (Top-of-Climb) and SLS (Sea Level Static). 
Table 5. N+2 Engine Modeling Results

\begin{tabular}{|c|c|c|c|c|c|c|c|c|c|c|}
\hline \multirow{3}{*}{$\begin{array}{l}\text { Vehicle Application } \\
\text { Architecture } \\
\text { Flight Condition }\end{array}$} & \multicolumn{2}{|c|}{$\begin{array}{c}\text { Regional Jet (T+W98, } \\
\text { OWN98) }\end{array}$} & \multicolumn{2}{|c|}{$\begin{array}{c}\text { Single Aisle (T+W160, } \\
\text { OWN160) }\end{array}$} & \multicolumn{2}{|c|}{$\begin{array}{l}\text { Small Twin Aisle and } \\
\text { VLTA (T+W216, } \\
\text { HWB216, T+W400) }\end{array}$} & \multicolumn{2}{|c|}{$\begin{array}{c}\text { Large Twin Aisle } T+W \\
\text { (T+W301-DD) }\end{array}$} & \multicolumn{2}{|c|}{$\begin{array}{l}\text { Large Twin Aisle } \mathrm{T}+\mathrm{W} \\
\text { (T+W301-GTF) }\end{array}$} \\
\hline & \multicolumn{2}{|c|}{ Direct Drive } & \multicolumn{2}{|c|}{ Geared } & \multicolumn{2}{|c|}{ Geared } & \multicolumn{2}{|c|}{ Direct Drive } & \multicolumn{2}{|c|}{ Geared } \\
\hline & TOC (ADP) & SLS & TOC (ADP) & SLS & TOC (ADP) & SLS & TOC (ADP) & SLS & TOC (ADP) & SLS \\
\hline Mach, Altitude & $0.8,35 \mathrm{kft}$ & 0,0 & $0.8,35 \mathrm{kft}$ & 0,0 & $0.8,35 \mathrm{kft}$ & 0,0 & $0.8,35 \mathrm{kft}$ & 0,0 & $0.8,35 \mathrm{kft}$ & 0,0 \\
\hline Net Thrust, Ibf & 3250 & 14690 & 4300 & 21550 & 8300 & 45800 & 15800 & 71885 & 16100 & 74170 \\
\hline Specific Fuel Consumption & 0.5245 & 0.2838 & 0.4834 & 0.1914 & 0.4648 & 0.1881 & 0.4784 & 0.2165 & 0.4567 & 0.1835 \\
\hline Overall Pressure Ratio & 35.0 & 28.7 & 35 & 24.85 & 50.0 & 38.5 & 60.0 & 43.25 & 60.0 & 40.1 \\
\hline Bypass Ratio & 9.7 & 10.0 & 23.45 & 27.4 & 21.75 & 24.75 & 14.65 & 17.3 & 20.6 & 25.0 \\
\hline Fan Pressure Ratio & 1.60 & 1.49 & 1.30 & 1.18 & 1.30 & 1.21 & 1.50 & 1.32 & 1.35 & 1.20 \\
\hline Bare Engine Weight & \multicolumn{2}{|c|}{2941} & \multicolumn{2}{|c|}{4727} & \multicolumn{2}{|c|}{10635} & \multicolumn{2}{|c|}{17036} & \multicolumn{2}{|c|}{18356} \\
\hline Accessories Weight & \multicolumn{2}{|c|}{459} & \multicolumn{2}{|c|}{714} & \multicolumn{2}{|c|}{1446} & \multicolumn{2}{|c|}{2061} & \multicolumn{2}{|c|}{2184} \\
\hline Engine Mount Weight & \multicolumn{2}{|c|}{60} & \multicolumn{2}{|c|}{98} & \multicolumn{2}{|c|}{218} & \multicolumn{2}{|c|}{344} & \multicolumn{2}{|c|}{372} \\
\hline Total Engine Weight & \multicolumn{2}{|c|}{3460} & \multirow{2}{*}{\multicolumn{2}{|c|}{5539}} & \multicolumn{2}{|c|}{12299} & \multicolumn{2}{|c|}{19441} & \multicolumn{2}{|c|}{20912} \\
\hline Inlet \& Nacelle Weight & \multicolumn{2}{|c|}{352} & & & \multicolumn{2}{|c|}{1370} & \multicolumn{2}{|c|}{1911} & 21 & \\
\hline Total Engine Pod Weight & 38 & & \multicolumn{2}{|c|}{6232} & 13 & & 213 & & 23 & \\
\hline Fan diameter (in) & 54 & & $84-x \cdot r \cdot r \cdot r$ & & 11 & & 13 & & & \\
\hline Engine Pod Length (in) & 11 & & 1 & & 20 & & 27 & & & \\
\hline Nacelle Max Diam (in) & 66 & & & & & & & & & \\
\hline
\end{tabular}

The weights data shown is for the uninstalled engines, and the performance estimates include a 200 horsepower extraction and no bleed. The no bleed architecture is consistent with the more electric airplane design philosophy that was incorporated for the $\mathrm{N}+2$ concepts. An additional 5\% of the total engine pod weight is added upon installation to account for the pylon and mounting structure weight for the $\mathrm{T}+\mathrm{W}$ and OWN concepts. An additional $12 \%$ of the total engine pod weight is added upon installation to account for the pylon and mounting structure weight for the HWB concepts. This value was derived from previous proprietary studies of engine installations on HWB concepts, and was also utilized for the MFN concept to account for the carry-through structure required for the fuselage side-mounted engines. The T+W98 and OWN98 designs utilized a small DD engine architecture, and the T+W160 and OWN160 utilized a small GTF engine architecture. The thrust levels are significantly less than current aircraft in these size classes due to the impact of the $\mathrm{N}+2$ technologies, which enable much lighter and more efficient airframes leading to lower thrust requirements. The T+W216 and HWB216 utilized two medium GTF engines, and the $\mathrm{T}+\mathrm{W} 400$ utilized four of the same medium GTF engines. The $\mathrm{T}+\mathrm{W} 301$ concept utilized both a large DD and a large GTF. The GTF fan diameter was significantly larger than the DD (151 vs. 131 inches), but the overall length was shorter ( 245 vs. 274 inches). The GTF total engine pod weight was $\sim 8 \%$ more than the DD weight, but the GTF SFC at TOC was $~ 5 \%$ lower. The large GTF engine was also utilized for the MFN301 concept.

Table 6 shows the N+2 engine modeling results for the large HWB concepts. A 132 inch fan diameter constraint was applied to the large HWB concept engines due to propulsion airframe integration requirements that were quantified under ITD51A. The constraint was active only in the case of the large GTF engine. A separate engine was also sized for the HWB400 since it is a three-engine design and required more thrust than was available from three of the medium GTF engines that were utilized for the twin-engine HWB216 and the four-engine T+W400. 
Table 6. N+2 Engine Modeling Results for the Large HWB Concepts

\begin{tabular}{|c|c|c|c|c|c|c|}
\hline \multirow{3}{*}{$\begin{array}{l}\text { Vehicle Application } \\
\text { Architecture } \\
\text { Flight Condition }\end{array}$} & \multicolumn{2}{|c|}{$\begin{array}{l}\text { Large Twin Aisle HWB } \\
\text { (HWB301-DD) }\end{array}$} & \multirow{2}{*}{\multicolumn{2}{|c|}{$\begin{array}{c}\text { Large Twin Aisle HWB } \\
\text { (HWB301-GTF, MFN301- } \\
\text { GTF) } \\
\text { Geared }\end{array}$}} & \multicolumn{2}{|c|}{$\begin{array}{c}\text { Very Large Twin Aisle } \\
\text { HWB (HWB400-GTF) }\end{array}$} \\
\hline & \multicolumn{2}{|c|}{ Direct Drive } & & & \multicolumn{2}{|c|}{ Geared } \\
\hline & TOC (ADP) & SLS & TOC (ADP) & SLS & TOC (ADP) & SLS \\
\hline Mach, Altitude & $0.8,35 \mathrm{kft}$ & 0,0 & $0.8,35 \mathrm{kft}$ & 0,0 & $0.8,35 \mathrm{kft}$ & 0,0 \\
\hline Net Thrust, Ibf & 13200 & 67230 & 12500 & 67420 & 10400 & 56170 \\
\hline Specific Fuel Consumption & 0.4850 & 0.2320 & 0.4644 & 0.1984 & 0.4651 & 0.1987 \\
\hline Overall Pressure Ratio & 60.0 & 48.9 & 60.0 & 47.1 & 60.0 & 47.2 \\
\hline Bypass Ratio & 12.85 & 14.4 & 17.65 & 20.0 & 17.6 & 19.95 \\
\hline Fan Pressure Ratio & 1.50 & 1.38 & 1.35 & 1.25 & 1.35 & 1.25 \\
\hline Bare Engine Weight & \multicolumn{2}{|c|}{14942} & \multicolumn{2}{|c|}{14968} & \multicolumn{2}{|c|}{12390} \\
\hline Accessories Weight & \multicolumn{2}{|c|}{1838} & \multicolumn{2}{|c|}{1841} & \multicolumn{2}{|c|}{1487} \\
\hline Engine Mount Weight & \multicolumn{2}{|c|}{302} & \multicolumn{2}{|c|}{303} & \multicolumn{2}{|c|}{251} \\
\hline Total Engine Weight & \multicolumn{2}{|c|}{17081} & \multicolumn{2}{|c|}{17112} & \multicolumn{2}{|c|}{14128} \\
\hline Inlet \& Nacelle Weight & \multicolumn{2}{|c|}{1687} & \multicolumn{2}{|c|}{1711.1} & \multicolumn{2}{|c|}{1464} \\
\hline Total Engine Pod Weight & \multicolumn{2}{|c|}{18768} & \multicolumn{2}{|c|}{18823} & \multicolumn{2}{|c|}{15591} \\
\hline Fan diameter (in) & \multicolumn{2}{|c|}{118.7} & \multicolumn{2}{|c|}{132.4} & \multicolumn{2}{|c|}{120.8} \\
\hline Engine Pod Length (in) & \multicolumn{2}{|c|}{272.9} & \multicolumn{2}{|c|}{230.5} & \multicolumn{2}{|c|}{217.5} \\
\hline Nacelle Max Diam (in) & \multicolumn{2}{|c|}{143.6} & \multicolumn{2}{|c|}{160.2} & \multicolumn{2}{|c|}{146.1} \\
\hline
\end{tabular}

Again, the weights data shown is for the uninstalled engines, and the performance data includes a 200 horsepower extraction and no bleed. In this case, the DD and GTF weights were similar, due to the active fan diameter constraint for the large HWB GTF engine. The GTF engine SFC is $\sim 4 \%$ lower than the DD at TOC.

\section{Advanced (N+2) Airframe Modeling}

The vehicle modeling process started with the identification of the suite of advanced technologies that would be utilized. As shown in Figure 1, the technology readiness level constraint for the N+2 timeframe is TRL 4-6 by 2020. Therefore, ERA Phase I and Phase II technologies were utilized, along with several other N+2 technologies that meet the TRL constraint but were not part of the ERA portfolio, such as riblet technology.

In the aerodynamics technology area, ITD12A+ targeted a transition Reynolds number for an upper wing surface chord laminar flow run of 35\% at the mean aerodynamic chord (MAC) for the SA class $\mathrm{T}+\mathrm{W}$ concept. Using this transition Reynolds number as an anchor point, adjustments were made for the larger vehicles to account for the sweep and Mach number effects using a proprietary Northrop Grumman natural laminar flow tool. Knock down factors (KDFs) were applied to account for the disruptions of laminar flow due to bug hits on the leading edges of the wing and tails. Although Krueger leading edge devices may protect the wing leading edge from bug hits, it was assumed the Krueger flaps would be retracted prior to the vehicle climbing out of the bug hit zone. As an example, without insect accretion mitigation (IAM) coatings, the KDF for the LTA class was estimated to be $12 \%$, which would result in a $12 \%$ subtractive reduction of chord laminar flow due to bug hits. With the IAM coatings, this KDF is reduced to $7 \%$, resulting in a reduction of laminar flow achieved (at the MAC) from $20 \%$ chord to $13 \%$ chord. The final adjustment assumed the use of discrete roughness elements (DREs) to extend the NLF run by a factor of 1.2 , as estimated by Malik, et al. ${ }^{20}$, resulting in an upper wing surface natural laminar flow run of $15 \%$ chord. Active laminar flow control technology was also examined, focusing on hybrid laminar flow control (HLFC) via suction technology. This technology can enable wing upper surface laminar flow runs of $50 \%$ chord, see Collier ${ }^{21}$, but requires additional equipment such as ducting, compressors, and control hardware and software. Based on a previous unpublished study, a value of $10.6 \mathrm{lb} / \mathrm{ft}$ was utilized to estimate the weight of this additional equipment. The length is defined as the linear running length of the system along the leading edge of the wing and tails. A $0.1 \%$ fuel flow increase was also modeled to account for the extra power required to run the suction system. As an example, for the case of the T+W301, the linear distance of the suction system was estimated to be $314 \mathrm{ft}$, resulting in a weight increase of $3328 \mathrm{lb}$. This weight increase is roughly equivalent to the weight of the air conditioning system in the baseline aircraft. In all cases the HLFC technology resulted in an overall system benefit compared to the NLF approach, and was therefore utilized for all of the N+2 vehicle models. 
As mentioned above, riblet technology was utilized to reduce turbulent skin friction drag. Wetted areas of the wing, horizontal tail, and nacelle were reduced to model turbulent skin friction drag reductions for riblets based on Walsh, Sellers and McGinley ${ }^{22}$ and a previous Boeing proprietary study. These wetted area reductions simulate the application of riblets to these areas, and directly reduce the skin friction drag of the vehicle. Table 7 summarizes the application of the HLFC and riblet aerodynamic technologies to the conventional $\mathrm{N}+2 \mathrm{~T}+\mathrm{W}$ vehicles.

Table 7. Laminar Flow (LF) and Riblet Technology Assumptions for N+2 Conventional T+W Concepts

\begin{tabular}{|r|c|c|c|c|c|}
\hline & $\mathbf{T + W 9 8}$ & $\mathbf{T + W 1 6 0}$ & $\mathbf{T + W 2 1 6}$ & $\mathbf{T + W 3 0 1}$ & $\mathbf{T + W 4 0 0}$ \\
\hline Total HLFC System Weight (Ib) & 1420 & 1834 & 2671 & 3328 & 4643 \\
\hline Wing (Upper/Lower) \%chord LF & $50 / 0$ & $50 / 0$ & $50 / 0$ & $50 / 0$ & $50 / 0$ \\
\hline Horiz. Tail (Upper/Lower) \%chord LF & $50 / 50$ & $50 / 50$ & $50 / 50$ & $50 / 50$ & $50 / 50$ \\
\hline Vert. Tail (Upper/Lower) \%chord LF & $50 / 50$ & $50 / 50$ & $50 / 50$ & $50 / 50$ & $50 / 50$ \\
\hline Nacelle (Upper/Lower) \%length LF & $38 / 38$ & $38 / 38$ & $36 / 36$ & $36 / 36$ & $35 / 35$ \\
\hline Wing Wetted Area & 0.97 & 0.97 & 0.97 & 0.97 & 0.97 \\
\hline Horizontal Tail Wetted Area & 0.97 & 0.97 & 0.97 & 0.97 & 0.97 \\
\hline Vertical Tail Wetted Area & 0.96 & 0.96 & 0.96 & 0.96 & 0.96 \\
\hline Fuselage Wetted Area & 0.94 & 0.94 & 0.94 & 0.94 & 0.94 \\
\hline Nacelle Wetted Area & 0.97 & 0.97 & 0.97 & 0.97 & 0.97 \\
\hline
\end{tabular}

Table 8 summarizes the application of the HLFC and riblet aerodynamic technologies to the unconventional N+2 concepts.

Table 8. Laminar Flow (LF) and Riblet Technology Assumptions for N+2 Unconventional Concepts

\begin{tabular}{|r|c|c|c|c|c|c|}
\hline & OWN98 & OWN160 & HWB216 & MFN301 & HWB301 & HWB400 \\
\hline Total HLFC System Weight (Ib) & 1357 & 1654 & 1972 & 3180 & 2162 & 2247 \\
\hline Wing (Upper/Lower) \%chord LF & $50 / 0$ & $50 / 0$ & $50 / 0$ & $50 / 0$ & $50 / 0$ & $50 / 0$ \\
\hline Horiz. Tail (Upper/Lower) \%chord LF & $50 / 50$ & $50 / 50$ & $\mathrm{~N} / \mathrm{A}$ & $50 / 50$ & $\mathrm{~N} / \mathrm{A}$ & $\mathrm{N} / \mathrm{A}$ \\
\hline Vert. Tail (Upper/Lower) \%chord LF & $50 / 50$ & $50 / 50$ & $50 / 50$ & $50 / 50$ & $50 / 50$ & $50 / 50$ \\
\hline Nacelle (Upper/Lower) \%length LF & $38 / 0$ & $38 / 0$ & $40 / 40$ & $40 / 40$ & $40 / 40$ & $40 / 40$ \\
\hline Wing Wetted Area & 0.97 & 0.97 & 0.95 & 0.97 & 0.95 & 0.95 \\
\hline Horizontal Tail Wetted Area & 0.97 & 0.97 & $\mathrm{~N} / \mathrm{A}$ & 0.97 & $\mathrm{~N} / \mathrm{A}$ & $\mathrm{N} / \mathrm{A}$ \\
\hline Vertical Tail Wetted Area & 0.96 & 0.96 & 0.95 & 0.96 & 0.95 & 0.95 \\
\hline Fuselage Wetted Area & 0.94 & 0.94 & 0.94 & 0.94 & 0.94 & 0.94 \\
\hline Nacelle Wetted Area & 0.97 & 0.97 & 0.96 & 0.97 & 0.96 & 0.96 \\
\hline
\end{tabular}

ITD $12 \mathrm{~A}+$ also contained research to mature active flow control (AFC) technology applied to a vertical tail. Based on an unpublished Boeing study, a 14\% reduction in vertical tail area was estimated for a mid-sized twin aisle class vehicle. This tail size reduction was applied to the $\mathrm{N}+2 \mathrm{~T}+\mathrm{W}$ vehicles but not to the HWB concepts.

ITD 21C focused on maturing the ACTE technology. This technology has the potential to reduce both structural weight and cruise drag by actively manipulating the wing trailing edge to optimize performance throughout the flight envelope. A 2015 Boeing systems study ${ }^{23}$ included an analyses of the ACTE impacts to an HWB design (the 0009H1), and two T+W designs (an STA with 222 passengers, and an SA, with 154 passengers). The ACTE system was applied only to the aft portion of the flap, allowing single slotted Fowler flap action in the low speed configuration, thus preserving high lift characteristics. The results showed significant wing box weight reductions for all cases, but at the expense of increased control surface weight. Overall, there is a clear system benefit to this technology. For the STA, the inboard aileron on the baseline vehicle handles roll control freeing up the outboard aileron for load alleviation. The addition of the ACTE technology augments this load alleviation capability, resulting in an overall wing weight reduction. For the SA, the baseline aircraft utilizes the outboard aileron for roll control and therefore limits the effectives of this control surface for load alleviation. The addition of the ACTE technology shifts roll control inboard thus partially freeing the outboard aileron for load alleviation. The overall wing weight benefit is positive, but not as much as seen for the STA case. For the HWB, the conclusion was the ACTE technology does 
not provide an overall system benefit. The HWB trailing edge has multiple control surfaces and the ACTE technology provides no additional flexibility to schedule the control surfaces beyond what is already inherent in the HWB design. Therefore, the ACTE technology was not applied to the HWB concepts. A drag reduction of $1 \%$ was applied assuming the use of the control surfaces to vary the camber during cruise for optimized performance based on the work of Szodruch ${ }^{24}$, Siclari ${ }^{25}$, and $\mathrm{Lyu}^{26}$. The last two rows in Table 9 and Table 10 show the FLOPS wing weight adjustments utilized to account for the ACTE technology.

In the weight reduction technology area, ITD21A focused on maturing a stitched, resin-infused (S/RI) composite approach. The PRSEUS implementation of the S/RI technology was utilized to build a multi-bay box (MBB) representative of an HWB centerbody cross section between the wings at $80 \%$ scale. Overall, the PRSEUS structure performed well and met its goals. Boeing performed a systems study to estimate the weight savings impacts of the S/RI technology for both T+W and HWB concepts. Using this information, FLOPS weight adjustment factors were derived for the N+2 concepts. Table 9 shows the derived FLOPS adjustment factors utilized for the conventional $\mathrm{T}+\mathrm{W}$ vehicles.

Table 9. FLOPS Conventional T+W Adjustment Factors for S/RI and ACTE Technology Impacts

\begin{tabular}{|r|c|c|c|c|c|}
\hline & $\mathbf{T + W 9 8}$ & $\mathbf{T}+\mathbf{W} \mathbf{1 6 0}$ & $\mathbf{T}+\mathbf{W} \mathbf{2 1 6}$ & $\mathbf{T}+\mathbf{W} \mathbf{3 0 1}$ & $\mathbf{T}+\mathbf{W} \mathbf{0 0 0}$ \\
\hline S/RI Wing Term 1 & $-21 \%$ & $-21 \%$ & $-21 \%$ & $-21 \%$ & $-21 \%$ \\
\hline S/RI Wing Term 2 & $-5 \%$ & $-5 \%$ & $-5 \%$ & $-5 \%$ & $-5 \%$ \\
\hline S/RI Wing Term 3 & $-5 \%$ & $-5 \%$ & $-5 \%$ & $-5 \%$ & $-5 \%$ \\
\hline S/RI HT and VT & $-21.0 \%$ & $-21.0 \%$ & $-21.0 \%$ & $-21.0 \%$ & $-21.0 \%$ \\
\hline S/RI Fuselage & $-5.0 \%$ & $-5.0 \%$ & $-5.0 \%$ & $-15.0 \%$ & $0.0 \%$ \\
\hline ACTE Wing box & $-13.2 \%$ & $-13.2 \%$ & $-18.9 \%$ & $-18.9 \%$ & $-18.9 \%$ \\
\hline ACTE Control Surfaces & $+9.9 \%$ & $+9.9 \%$ & $+9.9 \%$ & $+9.9 \%$ & $+9.9 \%$ \\
\hline
\end{tabular}

For the HWB concepts, Boeing utilized the most recent available PRSEUS data to estimate the weight savings when applied to an HWB. Previous studies from 2008 by Li and Velicki ${ }^{27}$, estimated a $10.3 \%$ weight savings relative to sandwich composites. The 2015 update showed an additional 7.8\% total body structural weight savings for a total of $18.1 \%$ weight savings relative to sandwich composites. A new FEM based HWB weight estimation tool called HWB Concept Design Structural analysis (HCDStruct) was created under ERA by Gern ${ }^{28,29}$ to capture these weight savings impacts of the PRSEUS technology. HCDStruct was utilized to provide direct estimates of the HWB structural weight which were input into FLOPS overriding the internal FLOPS weight estimation. HCDStruct was utilized to model the Boeing OREIO BWB design (open rotor propulsion version of BWB, see Pitera, et al. ${ }^{30}$ ), and the Boeing $-0009 \mathrm{H} 1 \mathrm{BWB}$ design. The $-0009 \mathrm{H} 1$ is the result of refinement conducted under ITD51A of the 0009A design that was developed under the ERA Advanced Vehicle Concepts (AVC) contract with Boeing ${ }^{31}$. Without any tweaking or calibration, HCDStruct estimated the OREIO structural weight to within $1 \%$ of the Boeing estimate, and to within $1.4 \%$ of the Boeing estimate for the $-0009 \mathrm{H} 1$. This benchmarking process provided confidence that HCDStruct results are consistent with Boeing BWB weight estimates. Table 10 shows the derived FLOPS adjustment factors utilized for the unconventional concepts. The MFN301 is a variant of the Boeing B27 design with the engines mounted in a mid-fuselage location which positions the engine inlet plane in line with the wing trailing edge to provide noise shielding. The concept utilizes a double-deck passenger layout to enable a more efficient engine carry-through integration. The B27 concept was developed as part of the previously mentioned ERA AVC study with Boeing (ref 28). 
Table 10. FLOPS Unconventional Concept Adjustment Factors for S/RI and ACTE Technology Impacts

\begin{tabular}{|r|c|c|c|c|c|c|}
\hline & OWN98 & OWN160 & HWB216 & MFN301 & HWB301 & HWB400 \\
\hline S/RI Wing Term 1 & $-21 \%$ & $-21 \%$ & HCDStruct & $-21 \%$ & HCDStruct & HCDStruct \\
\hline S/RI Wing Term 2 & $-5 \%$ & $-5 \%$ & HCDStruct & $-5 \%$ & HCDStruct & HCDStruct \\
\hline S/RI Wing Term 3 & $-5 \%$ & $-5 \%$ & HCDStruct & $-5 \%$ & HCDStruct & HCDStruct \\
\hline S/RI HT and VT & $-21.0 \%$ & $-21.0 \%$ & $-21.0 \%$ & $-21.0 \%$ & $-21.0 \%$ & $-21.0 \%$ \\
\hline S/RI Fuselage & $-5.0 \%$ & $-5.0 \%$ & HCDStruct & $0.0 \%$ & HCDStruct & HCDStruct \\
\hline ACTE Wing box & $-13.2 \%$ & $-13.2 \%$ & $0.00 \%$ & $-18.9 \%$ & $0.00 \%$ & $0.00 \%$ \\
\hline ACTE Control Surfaces & $+9.9 \%$ & $+9.9 \%$ & $0.00 \%$ & $+9.9 \%$ & $0.00 \%$ & $0.00 \%$ \\
\hline
\end{tabular}

ITD51A focused on the propulsion airframe integration (PAI) of UHB engines onto an HWB concept. Locating the engines well forward of the trailing edge improves the shielding effectiveness and lowers the overall noise; however, from an aerodynamic perspective the engines need to be located further aft to avoid locating the inlets in high speed/drag flow. In addition, the interference drag generated by the pylons and nacelles interacting with the body and the vertical tails must be minimized. Therefore, determining the optimum engine location and quantifying the installation drag is a complex but important challenge. The goal was to successfully integrate the engines with a drag penalty of no more than 2-3\%. Based on extensive CFD analyses and wind tunnel testing, the current engine installation drag penalty is estimated to be $1.4 \%$. The BWB-0009H1 is the configuration that emerged from this extensive analyses. This drag penalty is applied as an overall subsonic drag increase to the HWB concepts with the assumption that a similar level of performance to the BWB-0009H1 can be achieved. In addition, the engine installation geometry from the BWB-0009H1 was utilized to locate the engines on the N+2 HWB concepts. In addition to the PAI data that was utilized from this ITD, low speed aerodynamic performance as measured in the wind tunnel test was also utilized.

ITD50A focused on reducing flap side edge and landing gear noise. The noise reduction technologies and resulting performance impacts are detailed in Thomas, et al. ${ }^{32}$. The landing gear fairings were accounted for in the vehicle design by increasing the landing gear weight by $2 \%$. The flap side edge technology was weight neutral.

In addition to the ITD technology assumptions provided above, several $\mathrm{N}+2$ subsystem technologies were utilized. An advanced hybrid Solid Oxide Fuel Cell (SOFC)/gas turbine APU, see Daggett, et al. ${ }^{33}$, was assumed to be operable throughout the mission, thus partially relieving the engine from secondary system power requirements. The net benefit of reducing engine fuel flow while accounting for increased APU fuel flow was a $1 \%$ reduction in engine fuel flow. Finally, the more electric aircraft design philosophy was assumed to include electromechanical actuators (EMAs) along with the zero bleed engine architecture, see Blanding ${ }^{34}$. The EMAs are assumed to reduce the hydraulic system weight by $10 \%$.

The set of technology assumptions described above was then integrated into $\mathrm{N}+2$ vehicle models utilizing FLOPS. The optimization problem formulation described in Section III.A for the baseline vehicles was utilized to size the $\mathrm{N}+2$ vehicles with the addition of aspect ratio (AR) as a design variable, which was allowed to vary up to a maximum value of 11. For the HWB concepts, the planform was fixed, but the engine thrust was optimized. The starting design point for the HWB concepts was obtained from previous work by $\mathrm{Nickol}^{35}$.

For the low speed aerodynamic performance, a set of low speed takeoff and approach polars were estimated utilizing an updated version of the Modified Vortex Lattice (MVL-15) code ${ }^{18}$. MVL-15 was calibrated utilizing 737800 low speed aerodynamics data, and subsequently utilized to generate all of the $\mathrm{N}+2 \mathrm{~T}+\mathrm{W}$, MFN and OWN low speed polars. The low speed performance characteristics of the $\mathrm{N}+2$ designs drive the noise estimates, therefore several key parameters were monitored and adjusted during the sizing process. Approach speed was kept as low as possible to reduce airframe noise. Approach throttle setting was also kept as low as possible, but high enough to meet the missed approach constraint. Throttle setting at cutback was also kept as low as possible, but high enough to maintain flight on one engine after cutback. For the T+W301, a slightly non-optimum (in terms of min TOGW) thrust was specified to help reduce the cutback throttle setting. That is, the engines were sized at a higher thrust than needed to meet all of the constraints so that a larger cutback margin was obtained. This is one example of a direct tradeoff between fuel burn and noise performance. In the case of the HWB301-GTF, noise performance was reduced to improve fuel burn by constraining the GTF fan diameter to 132 inches. Larger fan diameters (and associated bypass ratios) help to reduce noise, but the larger and heavier engines are not optimum from a PAI and fuel burn perspective. Throughout the design process fuel burn and noise tradeoffs were made in an attempt to arrive at the best balanced design. 


\section{Noise and Emissions Modeling}

The focus of this study and the vehicle modeling analyses presented above has been on quantifying fuel burn reduction performance of advanced $(\mathrm{N}+2)$ concepts. As stated in the introduction and shown in Figure 1, noise and NOx emissions reductions are also part of the goal of ERA and will be briefly addressed in this section.

\section{A. Noise Modeling}

Data from the vehicle modeling work presented above, including low speed performance, takeoff and landing trajectories, engine source noise estimates, etc., was utilized by the ERA acoustics team to produce the noise assessment. This work can be found in Thomas, et.al..$^{32}$, and includes the analysis and results for the $\mathrm{N}+2$ concepts presented in this paper.

\section{B. Emissions Modeling}

For NOx emissions modeling, the landing and takeoff (LTO) cycle defined in the CAEP/6 regulations is intended to represent a single airplane operational cycle near airports. This cycle consists of four operational segments, each having a different throttle setting and time in mode. The parameter regulated, LTO NOx, is commonly written as Dp/Foo in the ICAO literature. Dp is the amount of NOx generated over the four segments of the operational cycle (in grams), and Foo is the maximum takeoff-rated sea level static thrust (in kilo-newtons). The thrust settings and times for the four segments in the landing-takeoff cycle are shown in Figure 2.

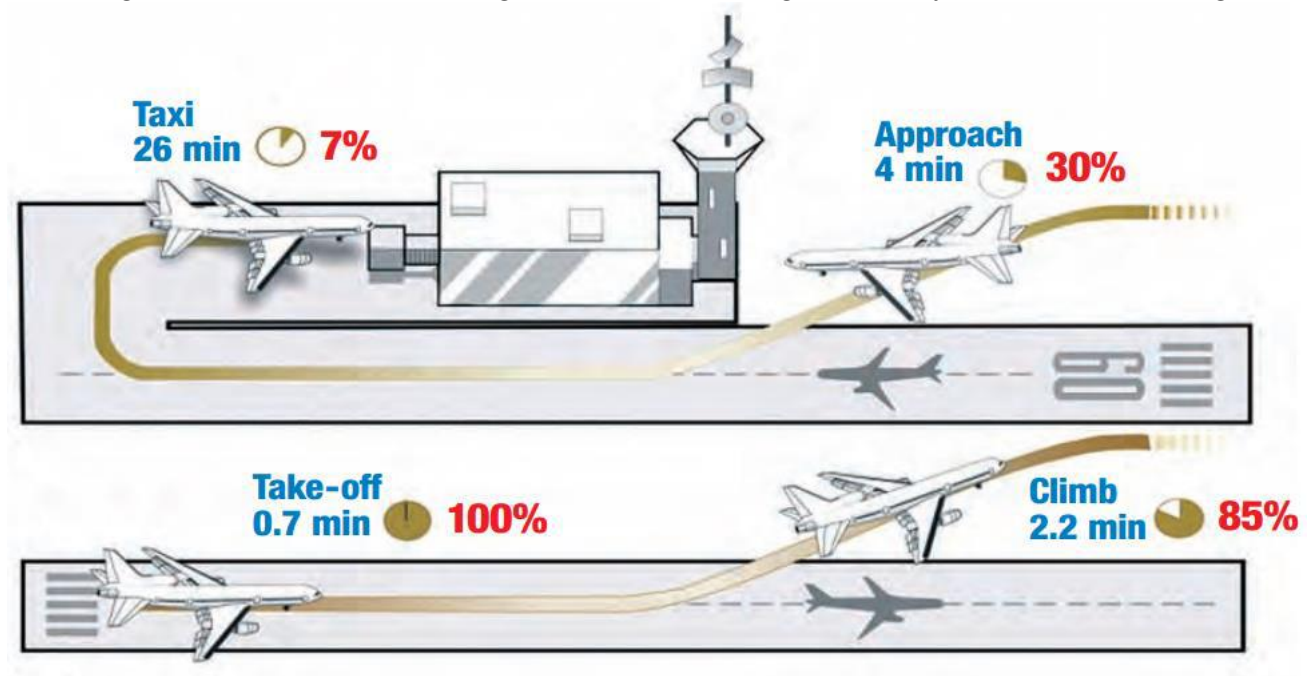

Thrust settings

Figure 2. Thrust settings and times for four operational segments.

Emissions modeling is based on data generated from ITD 40A. The systems analysis team utilized NASA derived NOx emission correlations based on sector-testing carried out under ITD 40A. The set of equations (shown below) was used in combination with NPSS representations of N+2 engine cycles to estimate LTO NOx values. P3 and $\mathrm{T} 3$ are the combustor inlet pressure and temperature and EINOx is the resulting NOx emissions index. 
With humidity correction, $\mathrm{P} 3$ in psia, $\mathrm{T} 3$ in $\mathrm{K}, \phi$ is fuel air equivalence ratio

$$
\begin{aligned}
& \text { Low Power (for } \phi<0.3, \mathrm{~T} 3<655 \mathrm{~K} \text {, and P3 }<690 \mathrm{Kpa}) \\
& \qquad E I N O_{x}=0.126 \times e^{\left(\frac{T_{3}}{195}\right)} \times P_{3}{ }^{0.25} \times\left(-3.12+\frac{-1.847}{\phi}+\frac{0.0585}{\phi^{2}}+\frac{5.02}{\sqrt{\phi}}\right)
\end{aligned}
$$

Low Power (for $\phi<0.3, \mathrm{~T} 3<655 \mathrm{~K}$, and P3 $>690 \mathrm{Kpa}$ )

$$
\begin{gathered}
E I N O_{x}=0.0113 \times e^{\left(\frac{T_{3}}{195}\right)} \times P_{3}{ }^{0.48} \times\left(-4.00+\frac{-2.17}{\phi}+\frac{0.0623}{\phi^{2}}+\frac{6.324}{\sqrt{\phi}}\right) \\
\text { High power (for } \phi>0.3 \text {, Т3 }>655 \mathrm{~K} \text {, and P3 }>1413 \mathrm{Kpa}) \\
E I N O_{x}=0.67 \times e^{\left(\frac{T_{3}}{171}\right)} \times\left(2.55+\frac{-3832}{P_{3}}+\frac{87}{\sqrt{P_{3}}}\right) \times\left(3.773+\frac{1.88}{\phi}+\frac{-0.0763}{\phi^{2}}+\frac{-5.014}{\sqrt{\phi}}\right)
\end{gathered}
$$

These values were then compared against the relevant ICAO stringency levels which are a function of engine overall pressure ratio, as shown in Figure 3. The ERA project LTO NOx target is relative to CAEP/6, or Tier 6 as it is more commonly referred to at present, represented by the solid blue line in Figure 3 below. The lighter solid blue line represents a $60 \%$ reduction which is both the NASA N+1 target and the FAA's CLEEN (Continuous Lower Energy, Emissions, and Noise) program target. The solid green line represents the NASA ERA N+2 target of $75 \%$ reduction.

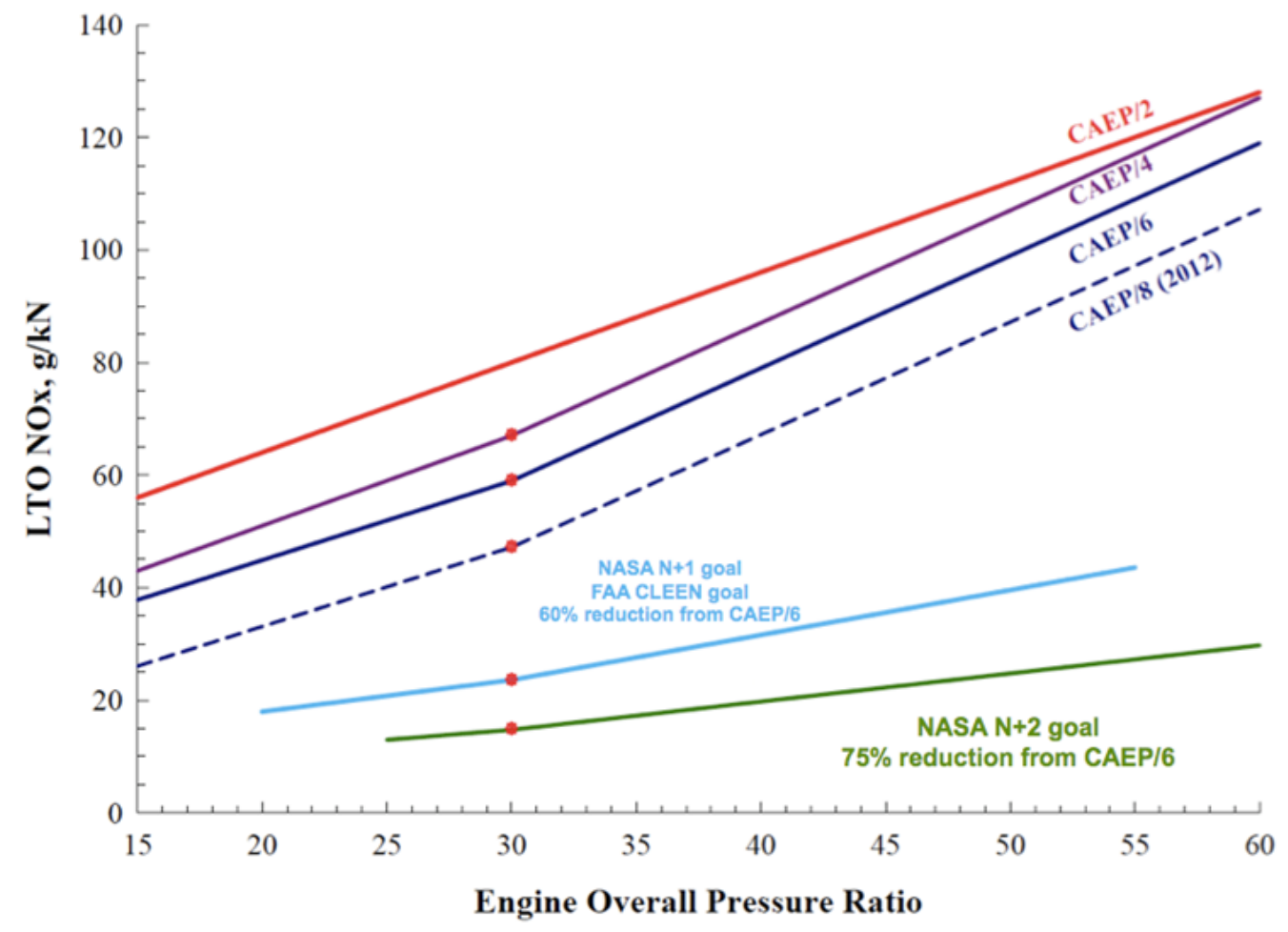

Figure 3. LTO NOx levels as a function of engine overall pressure ratio.

\section{Results and Conclusions}

The technology and modeling assumptions presented in Section III.B and C were utilized to generate optimized $\mathrm{N}+2$ concepts that provided the basis for estimating the fuel burn, noise and emissions performance as compared to the ERA goals.

Table 11 shows the results for the RJ and SA designs, both $\mathrm{T}+\mathrm{W}$ and OWN concepts. 
Table 11. N+2 Regional Jet and Single Aisle Class T+W and OWN Concepts

\begin{tabular}{|c|c|c|c|c|c|}
\hline & & \multicolumn{2}{|c|}{ Regional Jet } & \multicolumn{2}{|c|}{ Single Aisle } \\
\hline & Units & T+W98-DD & OWN98-DD & $T+W 160-G T F$ & OWN160-GTF \\
\hline TOGW & $\mathrm{lb}$ & 90,858 & 89,790 & 146,251 & 141,868 \\
\hline OEW & $\mathrm{Ib}$ & 53,631 & 52,861 & 81,688 & 78,377 \\
\hline Payload & $\mathrm{Ib}$ & 21,605 & 21,605 & 37760 & 37760 \\
\hline \# Pax & & 98 & 98 & 160 & 160 \\
\hline Range & $\mathrm{nm}$ & 2400 & 2400 & 2875 & 2875 \\
\hline Total Fuel & $\mathrm{lb}$ & 15,623 & 15,324 & 26,803 & 25,731 \\
\hline Block Fuel & $\mathrm{Ib}$ & $13,025(-46.3 \%)$ & $12,749(-47.3 \%)$ & $22,361(-42.8 \%)$ & $21,404(-45.3 \%)$ \\
\hline Wing Area & $\mathrm{ft}^{2}$ & 855 & 844 & 1179 & 1145 \\
\hline Wing Span & $\mathrm{ft}$ & 97.0 & 96.9 & 114 & 112.2 \\
\hline Wing Aspect Ratio & & 11.0 & 11.0 & 11.0 & 11.0 \\
\hline Wing Loading & $\mathrm{lb} / \mathrm{ft}^{2}$ & 106.2 & 105 & 124 & 124 \\
\hline Cruise Mach & & 0.78 & 0.78 & 0.78 & 0.78 \\
\hline Start of Cruise L/D & & 19.4 & 19.7 & 19.3 & 19.6 \\
\hline Number of Engines & & 2 & 2 & 2 & 2 \\
\hline Thrust per Engine & $\mathrm{lb}$ & 15,000 & 15,000 & 21,500 & 21,600 \\
\hline Start of Cruise SFC & & 0.512 & 0.513 & 0.48 & 0.475 \\
\hline
\end{tabular}

The value in parenthesis in the "Block Fuel" row is the percent reduction in block fuel burn relative to the baseline aircraft. The $\mathrm{N}+2$ concepts were able to meet the same requirements and constraints as the baseline aircraft, but with significantly reduced wing area and thrust, helping to further reduce weight (the baseline ERJ-190 OEW is $\sim 64,000 \mathrm{lb}$ compared to the T+W98 OEW of 53,600 lb) and fuel burn. The baseline ERJ-190 wing area is $\sim 1,000$ $\mathrm{ft}^{2}$, and the thrust per engine $\sim 20,000 \mathrm{lb}$, compared to the $\mathrm{T}+\mathrm{W} 98$ values of $855 \mathrm{ft}^{2}$ and $15,000 \mathrm{lb}$. 
Table 12 shows the results for the STA and VLTA designs, both the $\mathrm{T}+\mathrm{W}$ and the HWB concepts.

Table 12. N+2 Small Twin Aisle and Very Large Twin Aisle Class T+W and HWB Concepts

\begin{tabular}{|c|c|c|c|c|c|}
\hline & & \multicolumn{2}{|c|}{ Small Twin Aisle } & \multicolumn{2}{|c|}{ Very Large Twin Aisle } \\
\hline & Units & T+W216-GTF & HWB216-GTF & $T+W 400-G T F$ & HWB400-GTF \\
\hline TOGW & $\mathrm{lb}$ & 286,926 & 313,859 & 686,046 & 702,527 \\
\hline OEW & $\mathrm{lb}$ & 153,101 & 181,152 & 358,126 & 385,353 \\
\hline Payload & $\mathrm{lb}$ & 44,500 & 44,500 & 147,840 & 147,840 \\
\hline \# Pax & & 216 & 216 & 400 & 400 \\
\hline Range & $\mathrm{nm}$ & 6600 & 6600 & 5800 & 5800 \\
\hline Total Fuel & $\mathrm{lb}$ & 89,325 & 88,206 & 180,079 & 169,334 \\
\hline Block Fuel & $\mathrm{lb}$ & $80,188(-44.5 \%)$ & $79,078(-45.3 \%)$ & $160061(-46.2 \%)$ & $150,506(-49.4 \%)$ \\
\hline Wing Area & $\mathrm{ft}^{2}$ & 2975 & 8221 & 5549 & 11471 \\
\hline Wing Span & $\mathrm{ft}$ & 180.9 & 220 & 247.1 & 260 \\
\hline Wing Aspect Ratio & & 11.0 & 5.9 & 11.0 & 5.9 \\
\hline Wing Loading & $\mathrm{lb} / \mathrm{ft}^{2}$ & 96.4 & 38.2 & 123.6 & 61.2 \\
\hline Cruise Mach & & 0.8 & 0.8 & 0.85 & 0.85 \\
\hline Start of Cruise L/D & & 21.2 & 24.0 & 22.4 & 24.3 \\
\hline Number of Engines & & 2 & 2 & 4 & 3 \\
\hline Thrust per Engine & $\mathrm{Ib}$ & 45,327 & 45,566 & 44,707 & 54,648 \\
\hline Start of Cruise SFC & & 0.46 & 0.46 & 0.485 & 0.49 \\
\hline
\end{tabular}

Note the differences between the T+W and HWB concepts. The HWB concepts have a higher start of cruise $\mathrm{L} / \mathrm{D}$, resulting in a lower overall fuel burn. This fuel burn advantage grows with scale, but also requires a larger wingspan than the equivalent technology $\mathrm{T}+\mathrm{W}$ concept ( $260 \mathrm{ft} \mathrm{vs} 247 \mathrm{ft}$ for the VLTA concepts). 
Table 13 shows the $\mathrm{N}+2 \mathrm{~T}+\mathrm{W} 301$ and HWB301concepts, with DD and GTF engines.

Table 13. N+2 Large Twin Aisle class $\mathrm{T}+\mathrm{W}$ and HWB Concepts

\begin{tabular}{|c|c|c|c|c|c|}
\hline & & \multicolumn{4}{|c|}{ Large Twin Aisle } \\
\hline & Units & T+W301-DD & T+W301-GTF & HWB301-DD & HWB301-GTF \\
\hline TOGW & $\mathrm{lb}$ & 570,195 & 570,533 & 537,641 & 534,491 \\
\hline OEW & $\mathrm{lb}$ & 265,290 & 270,084 & 251,281 & 253,326 \\
\hline Payload & $\mathrm{Ib}$ & 118,100 & 118,100 & 118,100 & 118,100 \\
\hline \# Pax & & 301 & 301 & 301 & 301 \\
\hline Range & $\mathrm{nm}$ & 7500 & 7500 & 7500 & 7500 \\
\hline Total Fuel & $\mathrm{lb}$ & 186,805 & 182,349 & 168,259 & 163,065 \\
\hline Block Fuel & $\mathrm{Ib}$ & $168,687(-39.1 \%)$ & $164,748(-40.6 \%)$ & $151,597(-45.3 \%)$ & $147,011(-47.0 \%)$ \\
\hline Wing Area & $\mathrm{ft}^{2}$ & 4664 & 4670 & 10169 & 10169 \\
\hline Wing Span & $\mathrm{ft}$ & 226.5 & 226.6 & 250 & 250 \\
\hline Wing Aspect Ratio & & 11 & 11.0 & 6.2 & 6.1 \\
\hline Wing Loading & $\mathrm{lb} / \mathrm{ft}^{2}$ & 122.2 & 122.2 & 52.9 & 55.9 \\
\hline Cruise Mach & & 0.84 & 0.84 & 0.84 & 0.84 \\
\hline Start of Cruise L/D & & 22.1 & 22.0 & 23.8 & 23.7 \\
\hline Number of Engines & & 2 & 2 & 2 & 2 \\
\hline Thrust per Engine & $\mathrm{Ib}$ & 71800 & 74,000 & 65,989 & 69,398 \\
\hline Start of Cruise SFC & & 0.483 & 0.467 & 0.49 & 0.475 \\
\hline
\end{tabular}

The HWB301-GTF was estimated to have a fuel burn reduction of $47 \%$ relative to the $777-200 \mathrm{LR}$ baseline. The HWB301 wingspan of $250 \mathrm{ft}$ is greater than the equivalent technology $\mathrm{T}+\mathrm{W}$ concepts which have spans of $\sim 226 \mathrm{ft}$, and much greater than the 777-200 baseline which has a wingspan of $\sim 212 \mathrm{ft}$. Previous unpublished HWB planform studies have shown that HWB concepts tend to optimize at higher wingspans then their $\mathrm{T}+\mathrm{W}$ counterparts. Airport compatibility constraints may require wing tip folding capability for these higher span HWBs, similar to what is planned for the Boeing 777X. 
Table 14 shows the final N+2 concept which was the MFN301-GTF. The MFN301-GTF is also estimated to have a $47 \%$ fuel burn reduction relative to the $777-200 \mathrm{LR}$ baseline.

Table 14. MFN301-GTF Concept (Mid-Fuselage-Nacelle, 301 passengers, Geared Turbofan Engine)

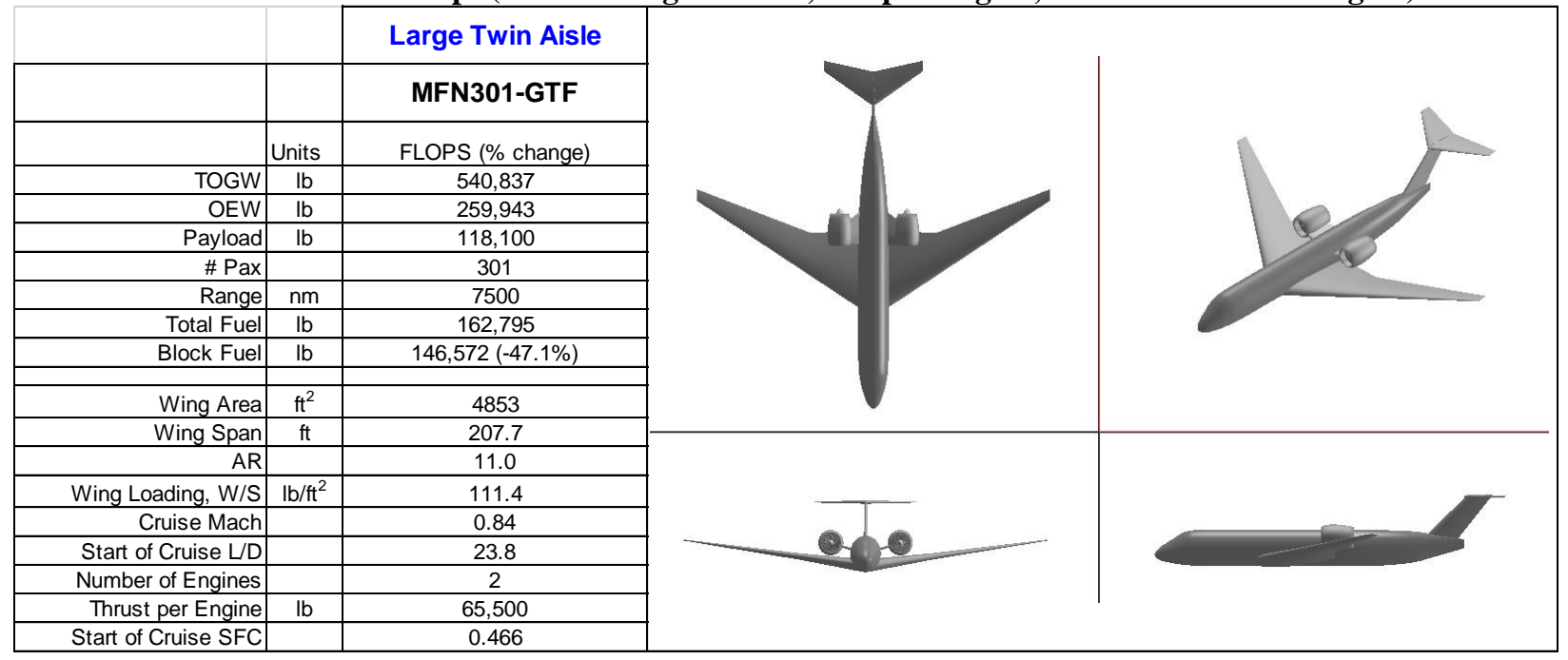

Figure 4 presents a summary of the fuel burn reductions for all of the N+2 concepts, with the ERA target of 50\% shown by the red line. Although there were no $\mathrm{N}+2$ concepts estimated to meet the target, several concepts reached $47 \%$ and the HWB400 was estimated to have a $49.4 \%$ reduction, relative to the $747-400$ baseline.

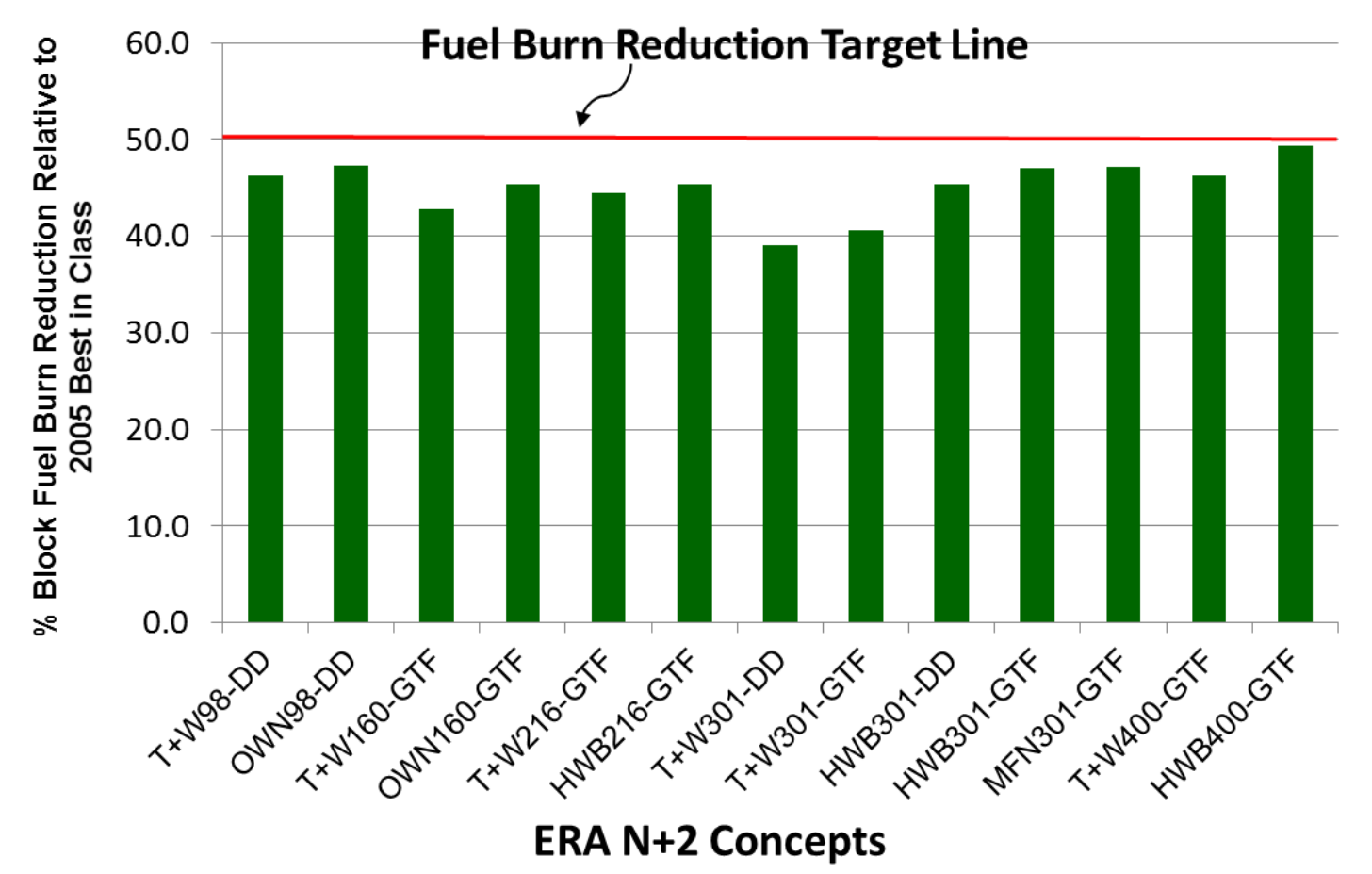

Figure 4. Summary of the fuel burn reduction estimates for the ERA N+2 concepts.

Figure 5 shows the summary of LTO NOx emissions reductions relative to the CAEP/6 rule. The ERA target of a $75 \%$ reduction is shown by the red line. Almost all of the $\mathrm{N}+2$ engines were able to meet the ERA target by utilizing the advanced combustor technology from ITD 40A. 


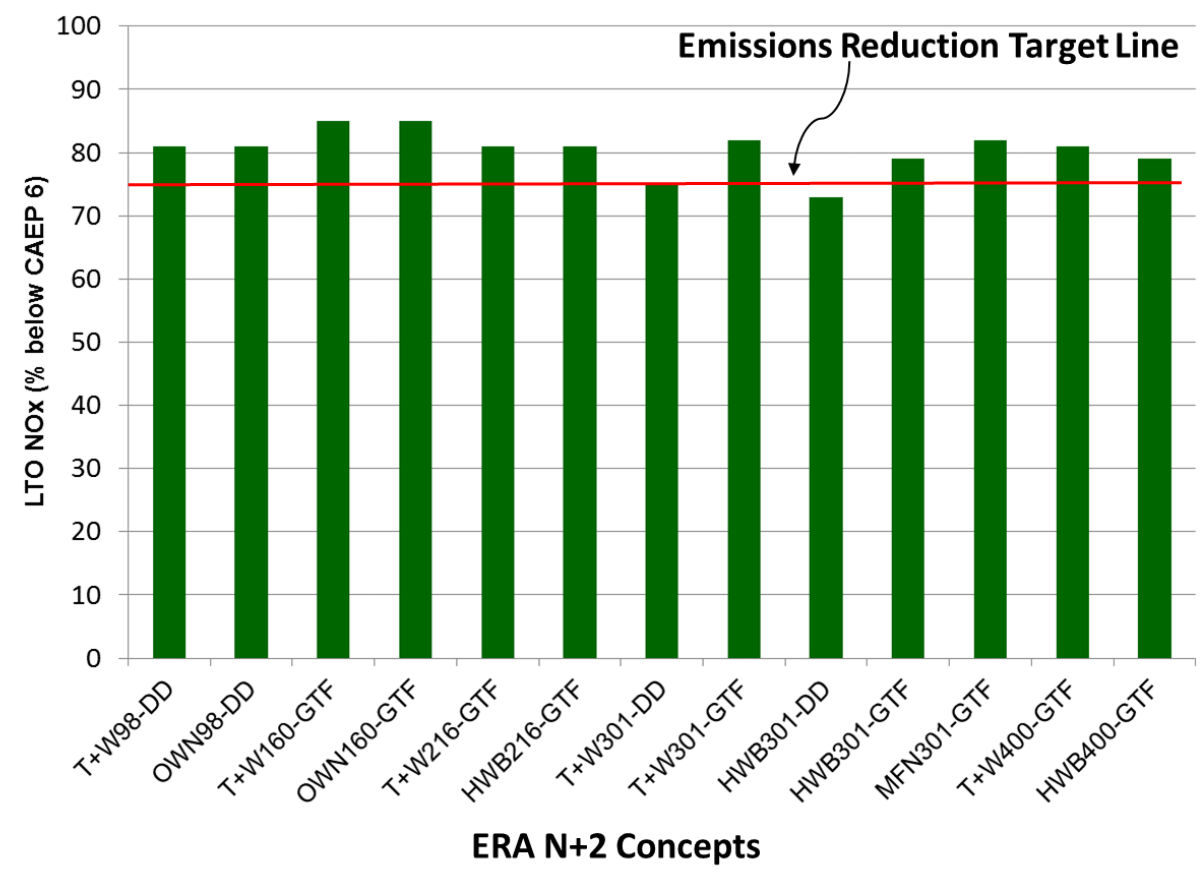

Figure 5. Summary of the LTO NOx emissions reduction estimates for the ERA N+2 concepts.

Detailed results of the noise assessment of the ERA N+2 concepts can be found in Thomas, et al. ${ }^{32}$, Figure 6 below summarizes the results. The red line shows the ERA target of 42 cum EPNL below Stage 4.

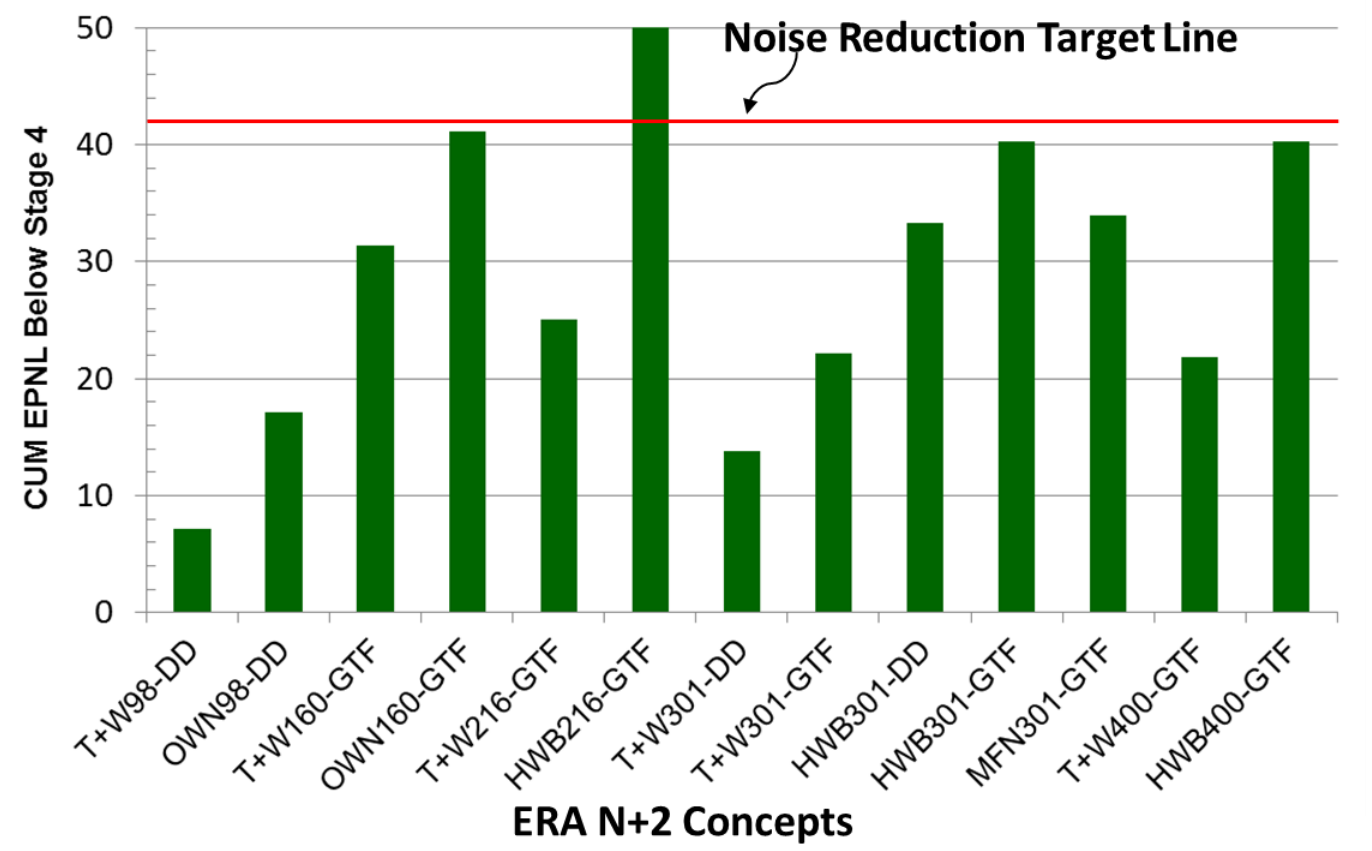

Figure 6. Summary of the noise reduction estimates for the ERA N+2 concepts.

The HWB216-GTF was the only concept to meet or exceed the noise target. This is mainly attributable to the relatively low 115 knot approach speed achieved by the HWB216. The low approach speed was a result of the low wing loading of $38 \mathrm{lb} / \mathrm{ft}^{2}$, due to significant weight savings from the ITD 21A PRSEUS and S/RI technology. As discussed in $\mathrm{Nickol}^{35}$ the HWB planforms were developed by wrapping the centerbody airfoils tightly around the pressurized payload volume and then designing the transition and outer wing sections based on maximizing 
aerodynamic efficiency while minimizing overall weight. The HWB planforms were then fixed, and only engine thrust was varied during the optimization. As the weight decreased significantly with a fixed planform, the wing loading also decreased. A future design iteration for the HWB216-GTF is needed to reduce the wetted area to improve the aerodynamic efficiency and reduce fuel burn. The wing loading and approach speed will increase, reducing the noise performance, but the overall concept should have improved fuel burn performance. This would be a more balanced design and might be able to meet all three ERA targets simultaneously.

Examining the noise, fuel burn, and emissions results, the HWB-GTF concepts provide the best overall performance and are summarized below in Table 15.

Table 15. N+2 HWB-GTF Concept Performance Summary

\begin{tabular}{|l|c|c|c|}
\hline & Noise & Fuel Burn & Emissions \\
\hline ERA Target & $\begin{array}{c}-42 \mathrm{~dB} \text { Cumulative } \\
\text { Margin to Stage 4 }\end{array}$ & $\begin{array}{c}-50 \% \text { Block Fuel Burn } \\
\text { Relative to 2005 Best- } \\
\text { in-Class }\end{array}$ & $\begin{array}{c}-75 \% \text { LTO Nox } \\
\text { relative to CAEP/6 }\end{array}$ \\
\hline HWB216-GTF & -51.9 & -45.3 & -81 \\
\hline HWB301-GTF & -40.3 & -47 & -79 \\
\hline HWB400-GTF & -40.3 & -49.4 & -79 \\
\hline
\end{tabular}

Although no one vehicle was estimated to simultaneously meet all three ERA N+2 targets, the HWB concepts came very close to meeting the aggressive ERA goal, and represent very significant advances in the state-of-the-art.

\section{Acknowledgments}

The authors would like to thank the ITD leads, and the ERA airframe, propulsion and acoustics teams for their contributions to the ERA systems analysis work presented above. In addition the authors acknowledge the ERA project manager, Fay Collier, for supporting this effort.

\section{References}

\footnotetext{
${ }^{1}$ Lin, John C., et al., "An Overview of Active Flow Control Enhanced Vertical Tail Technology Development,” AIAA SciTech 2016, San Diego, CA. (accepted for publication).

${ }^{2}$ Lin, John C., et al., "Innovative Flow Control Concepts for Drag Reduction,” AIAA SciTech 2016, San Diego, CA. (accepted for publication).

${ }^{3}$ Jegley, D., et al., "Development of Stitched Composite Structure for Advanced Aircraft," Paper \#1840, presented at American Society for Composites, 30th Technical Conference, East Lansing, MI, September, 2015.

${ }^{4}$ Li, V., Linton, K., "Hybrid Wing Body (HWB) Aircraft Design and Optimization using Stitched Composites," 33rd AIAA Applied Aerodynamics Conference, AIAA 2015-3289, June 2015.

${ }^{5}$ Miller, Eric J., et al., "Approach for Structurally Clearing an Adaptive Compliant Trailing Edge Flap for Flight," Paper \#46-22, 46th Annual Society of Flight Test Engineers International Symposium, Lancaster, CA, 14-17 September 2015.

${ }^{6}$ Herrera, Claudia Y., Spivey, Natalie D., Lung, Shun-fat, Ervin, Gregory, and Flick, Pete, “Aeroelastic Airworthiness Assessment of the Adaptive Compliant Trailing Edge Flaps," Paper \#46-23, 46th Annual Society of Flight Test Engineers International Symposium, Lancaster, CA, 14-17 September 2015.

${ }^{7}$ Miller, Eric J., Cruz, Josue, Lung, Shun-fat, "Hinge Moment Loads Measurement from a Seamless Compliant Trailing Edge Flap in Flight," AIAA SciTech 2016, San Diego, CA. (accepted for publication).

${ }^{8}$ Herrera, Claudia Y., Spivey, Natalie D., Lung, Shun-fat, Ervin, Gregory, and Flick, Pete, “Aeroelastic Response of the Adaptive Compliant Trailing Edge Transition Section," accepted for the AIAA SciTech 2016 Conference, January, 2016.

${ }^{9}$ Cruz, Josue and Miller, Eric J.; "Evaluation of Load Analysis Methods for NASA's GIII Adaptive Compliant Trailing Edge Project," AIAA SciTech 2016, San Diego, CA. (accepted for publication).

${ }^{10}$ Pratt \& Whitney, URL: http://www.pratt-whitney.com/PurePowerPW1000G Engine. Accessed 10/29/15.

${ }^{11}$ Van Zante, Dale E., Suder, Kenneth L., "Environmentally Responsible Aviation: Propulsion Research to Enable Fuel Burn, Noise and Emissions Reductions," ISABE-2015-20209, October, 2015.

${ }^{12}$ Khorrami, M.R., Humphreys, W.M., Lockard, D.P., and Ravetta, P.A., “Aeroacoustic Evaluation of Flap and Landing Gear Noise Reduction Concepts," AIAA Paper 2014-2478, 2014.

${ }^{13}$ Khorrami, M. R., Humphreys, Jr., W. M., and Lockard, D. P., "An Assessment of Flap and Main Landing Gear Noise Abatement Concepts," AIAA Paper 2015-2987, June 2015.
} 
${ }^{14}$ Flamm, J.D., James, K.D., Bonet, J.T., “Overview of ERA Integrated Technology Demonstration (ITD) 51A Ultra-High Bypass (UHB) Integration for Hybrid Wing Body (HWB)," AIAA SciTech 2016, San Diego, CA. (accepted for publication).

${ }^{15}$ Boeing Commercial Airplanes, "777-200LR / -300ER / -Freighter Airplane Characteristics for Airport Planning," D6-58329-2, Rev E, May 2015. URL: http://www.boeing.com/assets/pdf/commercial/airports/acaps/777_2lr3er.pdf. Accessed 10/20/2015. ${ }^{16}$ Claus, R. W.; et al., "Numerical Propulsion System Simulation," Computing Systems in Engineering, Vol. 2, No. 4, 1991, pp. 357-364.

${ }^{17}$ Tong, M. T.; and Naylor, B. A., “An Object-Oriented Computer Code for Aircraft Engine Weight Estimation,” GT2008-50062, ASME Turbo-Expo 2008, June 2008.

${ }^{18}$ Ozoroski, T.A., "Description, Usage, and Validation of the MVL-15 Modified Vortex Lattice Analysis Capability," NASA Contractor Report (to be published).

${ }^{19}$ McCullers, L, "Aircraft Configuration Optimization Including Optimized Flight Profiles," Proceedings of the Symposium of Recent Experiences in Multidisciplinary Analysis and Optimization, NASA CP 2327, April 1984.

${ }^{20}$ Malik, M., Liao, W., Li., Fei, Choudhari, M., "DRE-Enhanced Swept-Wing Natural Laminar Flow at High Reynolds Numbers," 51st AIAA Aerospace Sciences Meeting, AIAA 2013-0412, 2013.

${ }^{21}$ Collier, Jr., F.S., “An Overview of Recent Subsonic Laminar Flow Control Flight Experiments,” AIAA 24th Fluid Dynamics Conference, AIAA 93-2987, 1993.

${ }^{22}$ Walsh, M.J., Sellers III, W.L., McGinley, C.B., "Riblet Drag Reduction at Flight Conditions,” A88-40762, pp. 629-638.

${ }^{23}$ Wakayama, S., White, E.V., "Evaluation of Adaptive Compliant Trailing Edge Technology," 33rd AIAA Applied Aerodynamics Conference, AIAA 2015-3289, June 2015.

${ }^{24}$ Szodruch, J., "The Influence of Camber Variation on the Aerodynamics of Civil Transport Aircraft," AIAA 23rd Aerospace Sciences Meeting, AIAA-85-0353, 1985.

${ }^{25}$ Siclari, M.J., Austin, F., Van Nostrand, W., Volpe, G., "Optimization of Segmented Flaps for In-Flight Transonic Performance Enhancement," AIAA 35th Aerospace Sciences Meeting, AIAA-97-0516, 1997.

${ }^{26}$ Lyu, Z., Martins, J., "Aerodynamic Shape Optimization of an Adaptive Morphing Trailing Edge Wing," AIAA 2014-3275, June, 2014.

${ }^{27}$ Li, V., Velicki, A., "Advanced PRSEUS Structural Concept Design and Optimization,” 12th AIAA/ISSMO Multidisciplinary Analysis and Optimization Conference, AIAA 2008-5840, 2008.

${ }^{28}$ Gern, F.H., "Finite Element Based HWB Centerbody Structural Optimization and Weight Prediction," 53rd

AIAA/ASME/ASCE/AHS/ASC Structures, Structural Dynamics and Materials Conference, AIAA 2012-1606, 2012.

${ }^{29}$ Gern, F.H., "Conceptual Design and Structural Analysis of an Open Rotor Hybrid Wing Body Aircraft," 54th

AIAA/ASME/ASCE/AHS/ASC Structures, Structural Dynamics and Materials Conference, AIAA 2013-1688, 2013.

${ }^{30}$ Pitera, David M., et al., "Blended Wing Body Concept Development with Open Rotor Engine Integration," NASA/CR-2011217303, 2011.

${ }^{31}$ Bonet, J., Schellenger, H., Rawdon, B., Elmer, K., Wakayama, S., Brown, D., Guo, Y., "Environmentally Responsible Aviation (ERA) Project - N+2 Advanced Vehicle Concepts Study and Conceptual Design of Subscale Test Vehicle (STV)," NASA/CR-2013-216519, 2013.

32 Thomas, R.H., Burley, C.L., and Nickol, C.L., "Assessment of the Noise Reduction Potential of Advanced Subsonic Transport Concepts for NASA's Environmentally Responsible Aviation Project," AIAA SciTech 2016, San Diego, CA. (accepted for publication).

${ }^{33}$ Daggett, D., Rajashekara, K., Grieve, J., "Solid Oxide Fuel Cell/Gas Turbine Hybrid APU System for Aerospace Applications," 2006 IEEE Conference, 1-4244-0365-0/06, 2006.

${ }^{34}$ Blanding, D., "Subsystem Design and Integration for the More Electric Aircraft," AIAA 5th International Energy Conversion Engineering Conference, AIAA 2007-4828, 2007.

35 Nickol, Craig L., "Hybrid Wing Body Configuration Scaling Study," 50th AIAA Aerospace Sciences Meeting, AIAA $2012-$ 0337, 2012 